\title{
Cost of traumatic spinal cord injury in a population-based registry
}

\author{
Renee L Johnson ${ }^{1}$, CA Brooks ${ }^{2}$ and Gale G Whiteneck ${ }^{2}$ \\ ${ }^{I}$ Spinal Cord Injury Early Notification System ( A collaboration of Craig Hospital, Englewood, CO and Colorado \\ Department of Public Health and Environment, Denver, CO.); ${ }^{2}$ Craig Hospital, Englewood, Colorado, USA
}

\begin{abstract}
This prospective study examines a population based cohort of 115 Coloradans identified as having an acute traumatic spinal cord injury by the Spinal Cord Injury Early Notification System in 1989. Comprehensive medical cost and complication data were collected for the first 2 years of survival. Unlike previous cost studies, this group represents the broad spectrum of spinal cord injured persons, reflected in a truly population based sample. Nearly 22 million dollars were spent during the first 2 years post injury on behalf of these Coloradans. Care provided to the 27 persons with Frankel A, B or C tetraplegia accounted for $\$ 10.9$ million $(50 \%)$; $\$ 7.6$ million $(35 \%)$ was spent providing care for the 36 people with Frankel A, B or C paraplegia; and the remaining $\$ 3.3$ million $(15 \%)$ was required for services provided to the 52 persons who had resolved to either Frankel D or E at acute care discharge. Of the $\$ 6.3$ million that was spent post hospital discharge, $\$ 2.5$ million $(39 \%)$ is directly attributable to in-home care, and another $\$ 2.0$ million $(32 \%)$ is directly attributable to secondary medical complications. The most expensive complications occurred in the neurological, skin, respiratory and orthopedic body systems.
\end{abstract}

Keywords: spinal cord injury; costs; outcomes; complications; secondary conditions

\section{Introduction}

Injuries of all etiologies and severity are an important contributor to the health care burden of Americans. Rice and MacKenzie report that the total lifetime cost for the 57 million persons who sustained injuries in the United States during 1985 will impose a $\$ 158$ billion burden on the national economy. Although spinal cord injury (SCI) is proportionately rare as compared to other injuries (according to Rice and MacKenzie, those who survived traumatic SCI accounted for only $0.6 \%$ of persons hospitalized for an injury in $1985^{1}$ ) its results are frequently life changing and demand a high volume of medical services over the lifetime of the survivor. Lifetime cost projections for an individual surviving a spinal cord injury is in excess of one million dollars. ${ }^{2} \cdot 4$

Early work in the area of describing the cost of spinal cord injuries can be divided into two categorical groups. First, there is the work that focused on a particular etiology of injury, ${ }^{5-8}$ including motor vehicle crashes and occupational incidents. Since the spectrum of SCI severity differs with causes of SCI, these studies are not generalizable to the whole population of spinal cord injured persons.

Second, a number of studies focus on data from a specific hospital or hospital system that specialize in the treatment of persons with SCI. ${ }^{9-18}$ The numerous studies presented by the Model Regional SCI Centers make up the bulk of these facility-specific studies.

Correspondence: RL Johnson
Contributions from the Model Systems include works that are focused at only one facility ${ }^{9,15}$ and those that were an aggregate of more than one Model System Hospital's data. ${ }^{10-14}$ Other facility-specific studies include a pair of studies from Independent Living Centers in Boston and Worcester, MA ${ }^{17,18}$ and a contribution from Toronto Canada. ${ }^{16}$ Again, these works focus on describing the experiences of specialized SCI treatment centers.

Each of the preceding studies has made important contributions to the understanding of the costs associated with spinal cord injury. However, both individually and corporately, they fail to describe the breadth of cost that is experienced by persons of all etiologies of SCI or by persons seen at all types of medical facilities. Most importantly, these previous studies do not give adequate consideration to persons who sustain a SCI and have significant enough recovery so as to be discharged directly home from the acute care hospital. They have, indeed laid the foundation for a new spectrum of SCI cost investigations that are more representative of all SCI survivors regardless of their treatment facility or etiology of injury.

This new category of work has not only moved toward including a more complete spectrum of persons with SCI, but it has been more extensive in its approach to obtaining accurate measures of costs. To date two major contributions have been made with this broader perspective as the goal. The first is the work of Michael J DeVivo et al entitled the Economic Impact of Spinal 
Cord Injury; ${ }^{4}$ the second is the work of Monroe Berkowitz et al entitled The Economic Consequences of Traumatic Spinal Cord Injury. ${ }^{2,3}$

DeVivo and colleagues conducted a prospective one year cost study which occurred during 1989 and 1990. A random sample of 508 previous participants in the Model System National SCI Database and 227 newly injured participants in the National SCI Database were selected. One year of total SCI related medical charge data were collected through the use of periodic telephone interviews and National SCI Database abstraction. Charges were verified by either the provider or the third party payor. DeVivo reports a first year mean cost (1992 dollars) of $\$ 198,335$ and mean annual follow-up year charges of $\$ 24,154$ per spinal cord injured person. The most severely injured group of patients had mean first year charges of $\$ 417,067$ while the least severely injured group's mean first year charges were $\$ 122,914$. Similarly, the most severely injured group's mean annual follow-up charges were higher at $\$ 74,707$ while the least severely injured group's mean charges were considerably lower at $\$ 8614 .^{4}$

The strength of the DeVivo work is clearly in the methodological design of cost ascertainment. The approach is thorough and comprehensive and is based on actual documented charges. The weakness of this study is in the lack of representativeness of the sample of spinal cord injured individuals. Participants who experience SCI resulting in paralysis severe enough to be seen at specialty Model Systems Centers are not necessarily representative of all persons with SCI.

Berkowitz et al report an annual national expenditure of $\$ 3.4$ billion for the care of persons with traumatic spinal cord injuries (1988 dollars). They estimate an additional $\$ 2.2$ billion is accrued annually in indirect costs. This team investigated the costs accrued by a probability sample of 758 SCI persons living in both the community and institutional settings. This sample was drawn using a community sampling scheme, an institutional sampling scheme, and the Paralyzed Veterans of America's membership list. The participants responded to a detailed questionnaire. The services and medical items used by these persons were then given an estimated value based largely on average prices for hospitalization, practitioner visits, etc., calculated over the general US population. The 1988 pricing of medical goods and services was derived from a variety of secondary data sources, including government, industry and trade association publications. This study reports a mean first hospitalization and medical expense cost of over $\$ 95,000$, an average annual cost of over $\$ 14,000$. This study does not take into consideration any persons who did not survive their initial trauma or acute care phase of treatment. ${ }^{2,3}$ The Economic Consequences approach is superior for its case sampling design (it attempts to get a representative sample of all levels and functioning after spinal cord injury), however its weak link is in how the actual cost data were gathered. This study relied heavily upon estimating techniques for the cost of services and equipment.

Additionally, Price et al have reported inpatient hospitalization charges for the population based sample of persons registered by The Oklahoma Spinal Cord Injury Registry. ${ }^{19}$ While limited to only a portion of initial expenses, this work emphasizes the importance of cost studies addressing more representative samples.

The study presented here is the logical next step to these works. The population based registry group insures that the mixture of levels and severity of injuries that are included are really those that occur across a population. And, the thorough follow-up cost ascertainment strategies with collection of service provider names from medical record reviews and telephone interviews with participants, followed by collection of billing information directly from the providers, insures the accuracy of the cost data.

Two main study questions are addressed. What are the first two years of charges related to medical services for a population-based registry group of persons with SCI? What are the charges for followup complications among this population?

\section{Methodology}

Study population and classification

The study population includes all 115 cases of traumatic spinal cord injury, who survived to hospital admission, among Colorado residents, during 1989. This includes all cases identified by the Colorado Spinal Cord Injury Early Notification System (ENS), a statewide spinal cord injury surveillance effort, during the 1989 surveillance cycle. ${ }^{*}$ Completeness of statewide surveillance is assured by a multi-pronged method of case identification including both clinical liaisons phoning in new injuries and retrospective medical records surveillance using ICD-9 codes. Accuracy of the SCI diagnosis is assured by careful medical record review for spinal cord related neurological deficits prior to inclusion of cases into the data set. The recorded incidence of SCI during 1989 in Colorado was 36.5 cases per million who presented alive at the hospital emergency room. ${ }^{21}$ This rate is slightly higher than the often quoted incidence of 32.2 cases per million, reported by Kraus and colleagues, ${ }^{22}$ serving as additional evidence of the completeness of this population based group.

The severity of each participant's injury was classified by both the vertebral level of injury and by the Frankel Classification ${ }^{20}$ (rating of motor and sensory function below the level of injury) at the

\footnotetext{
*Five addtional cases, which occured during 1989, were identified during subsequent surveillance cycles and are not included in this report. All of these late identified cases had functional movement below their level of injury upon acute hospital discharge
} 
time of discharge from the acute care hospital. These two classifications were used to separate the participants into four groups based on the overall severity of their SCI. These groups are as follows: $\dagger$

Group 1: Injury level cervical 1-4 with Frankel Grade A, B or C (high tetraplegia).

Group 2: Injury level cervical 5-8 with Frankel Grade A, B or C (low tetraplegia).

Group 3: Thoracic, lumbar and sacral injury level with Frankel Grade of A, B, or C (paraplegia).

Group 4: All Frankel Grade D and E regardless of injury level (incomplete paralysis, typically allowing ambulation).

This classification scheme was chosen because of the functional similarity found within the groups. Under this scheme the potential for misclassification of cases is minimized. Since SCI survivors in each of the Frankel A, B and C categories function similarly, it is possible to achieve valid classification even in the absence of specific motor and sensory testing. $\ddagger$ Injuries that occurred to other body systems at the same time as the SCI was sustained have not been considered as a part of this study.

\section{Cost ascertainment}

Initials ENS case records and identification information were used to contact the 115 persons who were reported to the ENS during 1989 and solicit their participation in this study. Extensive interviews were conducted asking participants about their use of medical services, their procurement of medical supplies and durable medical equipment, their use of assistance in the home, and the names of all providers. Additionally, medical records of all hospital admissions were reviewed to identify additional providers. Billing information was obtained directly from providers.

The costs incurred during the first year are divided into specific service utilization categories. Additionally, data concerning volume of utilization have also been encoded for this study.

Data for each of the utilization categories have been classified for level of accuracy according to a threetiered scheme. (1) Actual documented costs for which a bill was obtained, (2) estimated costs based on identical services, and in rare instances, (3) estimated costs based on similar services.

The follow-up cost data were paired with a specific body system or nature of admission wherever possible. These body system classifications include: respiratory; urological/bladder/renal; skin; gastro-intestinal; neuro-

†While 14 participants experienced enough recovery after acute care discharge to switch groups at some point during the 2 year study, all participants were retained in their original groupings for analysis. †isclassification, should it have occurred at the time of original coding of the ENS records would have been more likely to have taken place within the Frankel Classifications of $\mathrm{A}, \mathrm{B}$ and $\mathrm{C}$, or within the Frankel Classifications of $\mathrm{D}$ and $\mathrm{E}$ rather than across these two major groups. Combining Frankel Classifications in this way minimizes the effects of initial errors in coding. The use of this scheme is also supported by DeVivo et al. $^{4}$ logical; orthopedic; injury; pain; gynecological; psychological; circulatory; concomitant injury; endocrine; fatigue; general follow-up.

All costs for the 2-year period have been adjusted to the 1992 dollar value, using the Medical Care Component of the Consumer Price Index. Statistical comparisons between the four injury groups were made using the Kruskal-Wallis non-parametric method for analysis of variance.

\section{Results}

Of the 115 participants of this study 11 were categorized as Group 1 (high tetraplegia), 16 as Group 2 (low tetraplegia), 36 as Group 3 (paraplegia)and 52 as Group 4 (incomplete paralysis). Onehundred and six of the participants survived into their second year post injury. **For those who died, cost data have been included for the period between injury and death and then the participant was excluded from subsequent analysis periods. Among the 115, 82 (71\%) agreed to provide the requested interview. For the remaining $29 \%$, medical record reviews served as the source of providers and follow-up care. This information source was available on all the cases, regardless of their participation with the interview, since SCI is a reportable condition in Colorado.

A total of 8864 hospital days were used by the study participants. Additionally, 1178 extended care facility days were used. Of the hospitalization days, 2695 were spent in initial acute care, 5564 were spent in initial rehabilitation and 605 were readmission days. Figure 1 shows the mean, median, interquartile range, and maximum and minimum length of hospitalization stays for the 106 persons who survived into their second year post injury, by injury severity group. Length of initial hospitalization (including both acute care and rehabilitation hospitalization) is significantly associated with injury severity $\left(\chi_{3}^{2}=53.75, P<0.001\right)$, however, length of readmission was not $\left(\chi_{3}^{2}=8.84\right.$, $P=0.051)$. It should be noted that the median number of readmission days for the low tetraplegia, the paraplegia, and the incomplete paralysis groups were all zero days.

A total of $\$ 21,727,290$, in 1992 dollars, has been documented as the first 2-year charges incurred by this population of $115 \mathrm{SCI}$ survivors. Of this, $\$ 17,624,900$ $(81.1 \%)$ are documented by the collection of actual

\footnotetext{
**Five participants with high tetraplegia died, one during acute care, two during rehabilitation and two during the second year post injury. Three participants with low tetraplegia died, one during acute care and two during the first year post injury. One participant with paraplegia died during the first year post injury. Two participants with incomplete paralysis died during the first year post injury.

Additionally, at the time of discharge from rehabilitation one of the Group 1 and one of the Group 2 participants remained ventilator dependent. The Group 1 participant who remained ventilator dependent at discharge from rehabilitation survived into their second year post injury, while the Group 2 participant was discharged after 180 days of rehabilitation to an acute care facility where they expired.
} 


\section{Figure 1: Total Days Hospitalized During Initial Admission and Follow-up Period \\ by Injury Group \\ $(n=106)$ *}

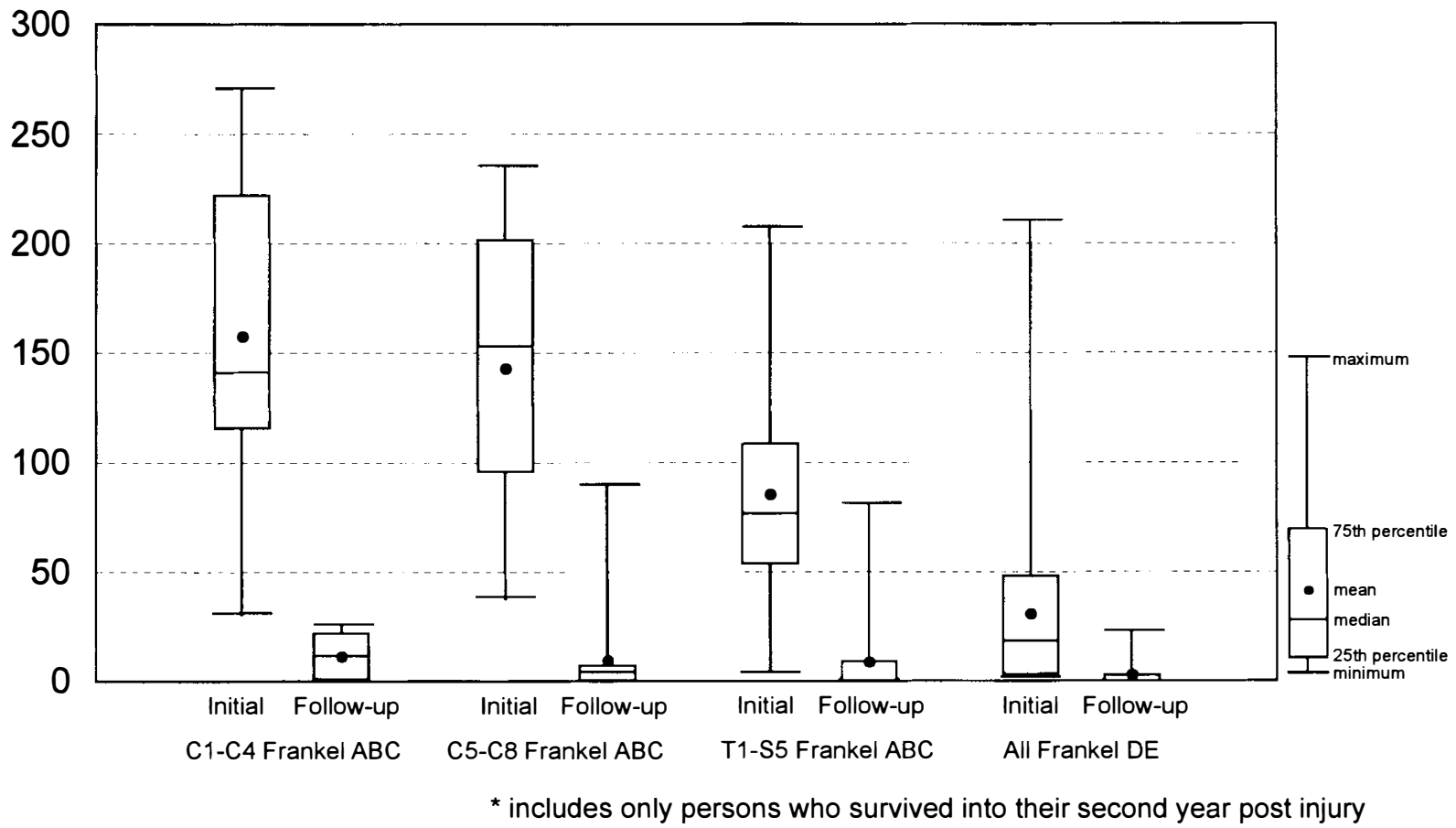

Table 1 Total charges in each data collection category by type of service (1992 Dollars)

\begin{tabular}{|c|c|c|c|c|}
\hline & Category 1* & Category 2** & Category $3 * * *$ & Total \\
\hline Initial hospitalization & $\begin{array}{r}\$ 14,809,143 \\
(95.8 \%)\end{array}$ & $\begin{array}{r}\$ 471,564 \\
(3.1 \%)\end{array}$ & $\begin{array}{r}\$ 173,305 \\
(1.1 \%)\end{array}$ & $\$ 15,454,013$ \\
\hline $\begin{array}{l}\text { Readmissions } \\
\quad \text { (including extended care) }\end{array}$ & $\begin{array}{r}\$ 880,004 \\
(77.6 \%)\end{array}$ & $\begin{array}{r}\$ 131,096 \\
(11.6 \%)\end{array}$ & $\begin{array}{l}\$ 122,941 \\
(10.8 \%)\end{array}$ & $\$ 1,134,040$ \\
\hline Outpatient services & $\begin{array}{r}\$ 636,821 \\
(87.8 \%)\end{array}$ & $\begin{array}{r}\$ 18,458 \\
(2.5 \%)\end{array}$ & $\begin{array}{r}\$ 70,395 \\
(9.7 \%)\end{array}$ & $\$ 725,673$ \\
\hline Physician services & $\begin{array}{r}\$ 304,054 \\
(71.3 \%)\end{array}$ & $\begin{array}{l}\$ 8,665 \\
(2.0 \%)\end{array}$ & $\begin{array}{r}\$ 113,716 \\
(26.7 \%)\end{array}$ & $\$ 426,465$ \\
\hline $\begin{array}{l}\text { Durable medical } \\
\text { equipment and home } \\
\text { modifications }\end{array}$ & $\begin{array}{r}\$ 674,718 \\
(60.6 \%)\end{array}$ & $\begin{array}{r}\$ 380,578 \\
(34.2 \%)\end{array}$ & $\begin{array}{r}\$ 57,454 \\
(5.2 \%)\end{array}$ & $\$ 1,112,750$ \\
\hline $\begin{array}{l}\text { Medication and } \\
\text { medical supplies }\end{array}$ & $\begin{array}{r}\$ 416,613 \\
(58.7 \%)\end{array}$ & $\begin{array}{l}\$ 38,481 \\
(15.4 \%)\end{array}$ & $\begin{array}{l}\$ 64,631 \\
(25.9 \%)\end{array}$ & $\$ 249,725$ \\
\hline In-home care**** & $\begin{array}{r}\$ 145,821 \\
(6.0 \%)\end{array}$ & $\begin{array}{r}\$ 1,970,423 \\
(80.4 \%)\end{array}$ & $\begin{array}{r}\$ 334,361 \\
(13.6 \%)\end{array}$ & $\$ 2,450,605$ \\
\hline Miscellaneous & $\begin{array}{r}\$ 27,725 \\
(15.9 \%)\end{array}$ & $\begin{array}{r}\$ 128,890 \\
(74.1 \%)\end{array}$ & $\begin{array}{l}\$ 17,403 \\
(10.0 \%)\end{array}$ & $\$ 174,018$ \\
\hline Total Dollars & $\begin{array}{r}\$ 17,624,900 \\
(81.1 \%)\end{array}$ & $\begin{array}{r}\$ 3,148,186 \\
(14.5 \%)\end{array}$ & $\begin{array}{r}\$ 954,205 \\
(4.4 \%)\end{array}$ & $\$ 21,727,290$ \\
\hline
\end{tabular}

${ }^{*}$ Category 1. Actual documented costs for which a bill was obtained. ${ }^{* *}$ Category 2 . Estimated costs based on identical services. ${ }^{* * *}$ Category 3 . Estimated costs based on similar services. ${ }^{* * * *}$ Includes attendent care, paid and unpaid comparable costs, registered nursing and household assistance 
hard copy bills. An additional $\$ 3,148,186(14.5 \%)$ are estimated by the receipt of an identical service for which we had an actual hard copy bill. The final $\$ 954,205(4.4 \%)$ are estimated by a similar service. Table 1 displays the percentages of data source used by type of service rendered. The actual documented costs of in-home care and miscellaneous expenses were the only service categories in which estimated costs exceeded actual documented costs. The majority of the estimating required in these two categories was the result of the $29 \%$ of the cases in which personal interviews were unable to be obtained.

Of the $\$ 21,727,290$ spent on providing care to this cohort of 115 survivors, care provided to the 11 persons with C1-C4 Frankel A, B or C tetraplegia accounted for $\$ 4,684,943(22 \%)$; care provided to the 16 persons with C5-C8 Frankel A, B or C tetraplegia accounted for another \$6,207,353 (29\%); \$7,582,693 $(35 \%)$ was spent providing care for the 36 people with Frankel A, B or C paraplegia; and the remaining $\$ 3,252,301(15 \%)$ was required for services provided to the 52 persons who had resolved to either Frankel D or $\mathrm{E}$ at acute care discharge.

The initial hospitalization phase, including both acute care and rehabilitation accounted for $\$ 15,454,013(71.1 \%)$ of the total dollars spent. Mean and median charges for hospitalization and physician care during the initial acute care and rehabilitation hospitalization periods are displayed, by injury group, in Table 2. Significant differences between injury groups $\left(\chi_{3}^{2}=52.2, \quad P<0.001\right)$, are seen during the initial hospitalization phase of care for hospitalization and physician charges during both the acute care and rehabilitation phases. Both of the tetraplegia groups had charges which were much greater than the charges for either the paraplegic or the incomplete paralysis groups.

The $\$ 6,273,277$ not spent on initial hospitalization and rehabilitation was spent on all categories of follow-up costs. During the period from initial discharge to the first year anniversary of injury a total of $\$ 3,258,140$ dollars was expended while $\$ 3,015,137$ dollars was spent in the second year after injury.

Table 3 presents the mean and median follow-up care dollar amounts, by injury group, for each of these categories of service during both the first year and the second year following injury. While the total costs for these years of follow-up differed by severity of injury $\left(n=106, \chi_{3}^{2}=60.0, P<0.001\right)$, it should be noted that during year one, readmission charges, physician charges and miscellaneous expenses did not differ significantly among the four severity groups. Similarly, the year two readmission charges and miscellaneous expenses did not differ significantly.

Within each of the four phases of care, acute care, rehabilitation, year one follow-up, and year two follow-up, the total charges generated during that

Table 2 Average initial hospitalization charges by type of service and injury group. (1992 Dollars)

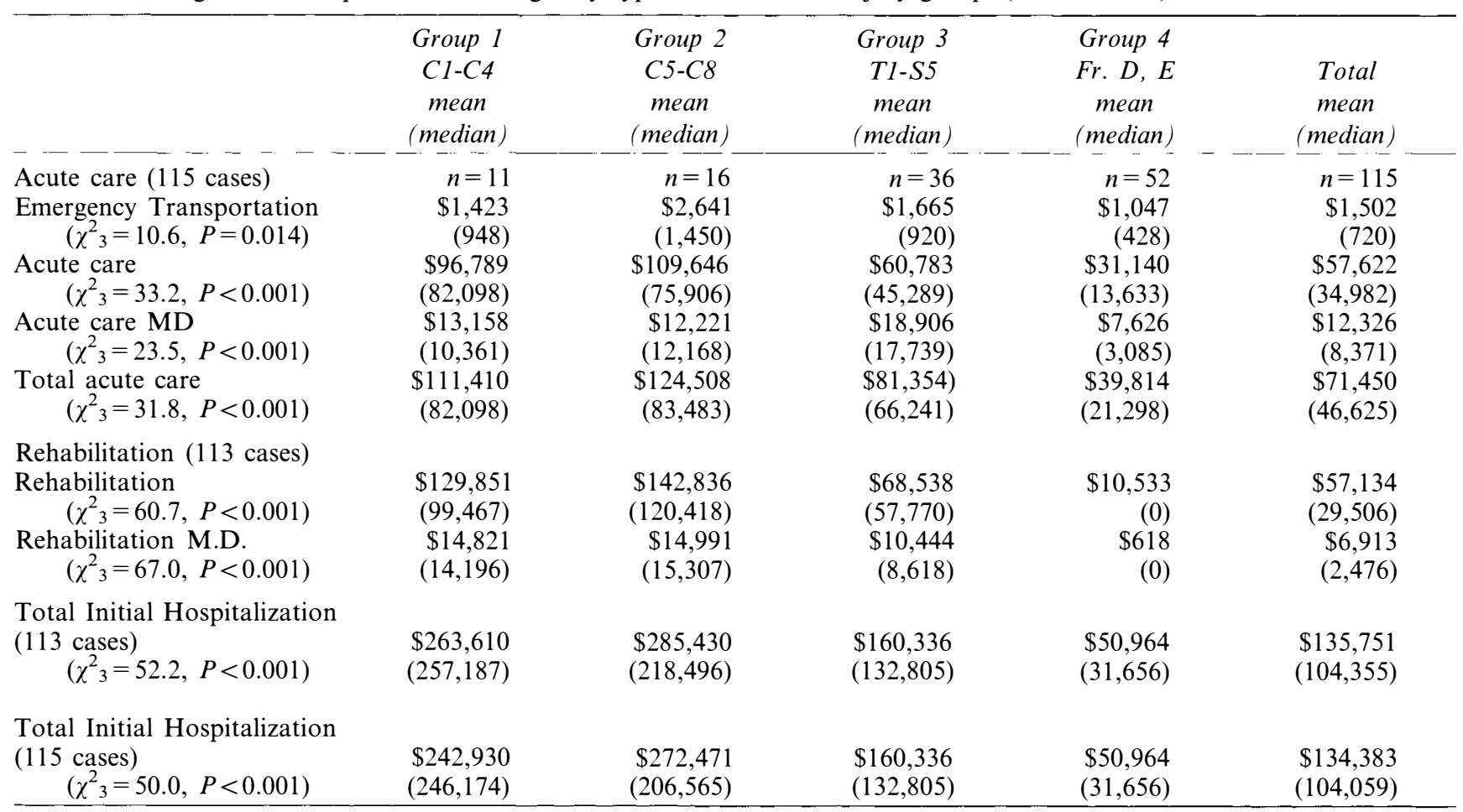


phase were significantly associated with the severity of injury group. Figure 2 displays the mean, median, interquartile ranges and range for both the initial inpatient and the follow-up periods of care.
To address the second major question of this study regarding the cost of secondary complications, the follow-up costs were analyzed in greater detail. Table 4 divides the total 2 year follow-up costs into two

Table 3 Average 2 year follow-up charges by type of service and injury group (1992 Dollars)

\begin{tabular}{|c|c|c|c|c|c|}
\hline $\begin{array}{l}\text { Year One } \\
\text { (111 cases) }\end{array}$ & $\begin{array}{l}\text { Group 1 } \\
\text { Cl-C4 } \\
\text { mean } \\
\text { (median) }\end{array}$ & $\begin{array}{l}\text { Group } 2 \\
\text { C5-C8 } \\
\text { mean } \\
\text { (median) }\end{array}$ & $\begin{array}{l}\text { Group } 3 \\
\text { TI-S5 } \\
\text { mean } \\
\text { (median) }\end{array}$ & $\begin{array}{l}\text { Group } 4 \\
\text { Fr. D,E } \\
\text { mean } \\
\text { (median) }\end{array}$ & $\begin{array}{c}\text { Total } \\
\text { mean } \\
\text { (median) }\end{array}$ \\
\hline $\begin{array}{l}\text { Readmissions (including } \\
\text { extended care) } \\
\left(\gamma^{2}=1.4, P=0.786\right)\end{array}$ & $\$ 10,219$ & $\$ 15,427$ & $\$ 1,729$ & $\$ 1,855$ & $\$ 4,251$ \\
\hline $\begin{array}{l}\left.\qquad \chi_{3}^{2}=1.4, P=0.786\right) \\
\text { Outpatient services }\end{array}$ & $\begin{array}{r}(0) \\
\$ 7.397\end{array}$ & $\begin{array}{r}(0) \\
\$ 3688\end{array}$ & $\begin{array}{r}(0) \\
\$ 4.954\end{array}$ & $\begin{array}{r}(0) \\
\$ 3,126\end{array}$ & $\begin{array}{r}(0) \\
\$ 4.102\end{array}$ \\
\hline$\left(\chi_{3}^{2}=12.5, P=0.006\right)$ & $(5,313)$ & $(3,164)$ & $\begin{array}{l}\$ 4,134) \\
(4,134)\end{array}$ & $(2,620)$ & $(3,126)$ \\
\hline $\begin{array}{l}\text { Physician charges } \\
\qquad\left(\chi^{2}{ }_{3}=3.4, P=0.334\right)\end{array}$ & $\begin{array}{l}\$ 2,427 \\
(1,462)\end{array}$ & $\begin{array}{r}\$ 2,216 \\
(437)\end{array}$ & $\begin{array}{r}\$ 1,372 \\
(931)\end{array}$ & $\begin{array}{l}\$ 2,162 \\
(1,425)\end{array}$ & $\begin{array}{l}\$ 1,932 \\
(1,038)\end{array}$ \\
\hline \multicolumn{6}{|l|}{ Durable medical } \\
\hline $\begin{array}{l}\text { modifications } \\
\qquad\left(\chi^{2}{ }_{3}=49.5, P<0.001\right)\end{array}$ & $\begin{array}{l}\$ 33,555 \\
(37,713)\end{array}$ & $\begin{array}{r}\$ 14,268 \\
(6,557)\end{array}$ & $\begin{array}{r}\$ 11,573 \\
(4,768)\end{array}$ & $\begin{array}{l}\$ 633 \\
(131)\end{array}$ & $\begin{array}{l}\$ 8,396 \\
(1,291)\end{array}$ \\
\hline \multicolumn{6}{|l|}{ Medication and medical } \\
\hline $\begin{array}{l}\text { supplies } \\
\qquad\left(\chi^{2}{ }_{3}=48.5, P<0.001\right)\end{array}$ & $\begin{array}{l}\$ 2,649 \\
(2,189)\end{array}$ & $\begin{array}{r}\$ 1,332 \\
(915)\end{array}$ & $\begin{array}{l}\$ 1,896 \\
(1,541)\end{array}$ & $\begin{array}{l}\$ 218 \\
(162)\end{array}$ & $\begin{array}{r}\$ 1,088 \\
(386)\end{array}$ \\
\hline In-home care* & $\$ 55,470$ & $\$ 22,011$ & $\$ 2,742$ & $\$ 1,074$ & $\$ 8,365$ \\
\hline$\left(\chi_{3}^{2}=24.3, P<0.001\right)$ & $(14,989)$ & $(3,090)$ & (211) & $(0)$ & (68) \\
\hline Micellaneous & $\$ 4,306$ & $\$ 2,784$ & $\$ 1,299$ & $\$ 234$ & $\$ 1,218$ \\
\hline$\left(\chi_{3}^{2}=4.1, P=0.291\right.$ & (345) & (0) & (182) & (91) & (141) \\
\hline $\begin{array}{l}\text { Total one year follow-up } \\
\qquad \chi^{2}{ }_{3}=35.9, P<0.001\end{array}$ & $\begin{array}{r}\$ 116,022 \\
(89,667)\end{array}$ & $\begin{array}{l}\$ 61,727 \\
(37,537)\end{array}$ & $\begin{array}{l}\$ 25,564 \\
(15,759)\end{array}$ & $\begin{array}{l}\$ 9,303 \\
(7,403)\end{array}$ & $\begin{array}{l}\$ 29,353 \\
(12,862)\end{array}$ \\
\hline \multicolumn{6}{|l|}{ Year Two (106 cases) } \\
\hline Readmission (including & $\$ 18,891$ & $\$ 5,259$ & $\$ 11,790$ & $\$ 600$ & $\$ 6,247$ \\
\hline extended care) & $(4,197)$ & (0) & (0) & $(0)$ & (0) \\
\hline$\left(\chi_{3}^{2}=9.5, P=0.070\right)$ & $\$ 8,232$ & $\$ 4,536$ & $\$ 3,541$ & $\$ 431$ & $\$ 2550$ \\
\hline Outpatient services & $(9,985)$ & $(3,127)$ & $(2,353)$ & (11) & (414) \\
\hline$\left(\chi^{2}{ }_{3}=33.6, P<0.001\right)$ & $\$ 3,049$ & $\$ 2,562$ & $\$ 3,218$ & $\$ 833$ & $\$ 2,000$ \\
\hline $\begin{array}{l}\text { Physician charges } \\
\qquad\left(\chi^{2}{ }_{3}=21.5, P<0.001\right)\end{array}$ & $(2,019)$ & $(1,469)$ & $(1,427)$ & (71) & (727) \\
\hline $\begin{array}{l}\text { Durable medical } \\
\text { equipment and home } \\
\text { modifications } \\
\qquad\left(\chi_{3}^{2}=25.6, P<0.001\right)\end{array}$ & $\begin{array}{l}\$ 7,814 \\
(1,287)\end{array}$ & $\begin{array}{r}\$ 2,190 \\
(398)\end{array}$ & $\begin{array}{r}\$ 2,456 \\
(820)\end{array}$ & $\begin{array}{r}\$ 77 \\
(0)\end{array}$ & $\begin{array}{r}\$ 1,705 \\
(0)\end{array}$ \\
\hline $\begin{array}{l}\text { Medication and medical } \\
\text { supplies }\end{array}$ & $\begin{array}{l}\$ 3,293 \\
(2,777)\end{array}$ & $\begin{array}{l}\$ 2,282 \\
(2,210)\end{array}$ & $\begin{array}{l}\$ 1,825 \\
(1,535)\end{array}$ & $\begin{array}{r}\$ 181 \\
(0)\end{array}$ & $\begin{array}{r}\$ 1,216 \\
(133)\end{array}$ \\
\hline $\begin{array}{l}\text { supplies } \\
\qquad\left(\chi^{2}{ }_{3}=35.3, P<0.001\right)\end{array}$ & $\begin{array}{l}(2,777) \\
\$ 92,441\end{array}$ & $\begin{array}{r}(2,210) \\
\$ 53,782\end{array}$ & $\begin{array}{l}(1,535) \\
\$ 2,184\end{array}$ & $\begin{array}{r}\text { (0) } \\
\$ 139\end{array}$ & $\$ 14,359$ \\
\hline In-home care* & $(13,990)$ & $(4,644)$ & $(0)$ & $(0)$ & $(0)$ \\
\hline$\left(\chi_{3}^{2}=42.4, P<0.001\right)$ & $\$ 1,847$ & $\$ 305$ & $\$ 422$ & $\$ 107$ & $\$ 367$ \\
\hline Miscellaneous & (0) & (74) & (0) & (0) & (0) \\
\hline$\left(\chi_{3}^{2}=4.7 P=0.304\right)$ & $\$ 135,568$ & $\$ 70,916$ & $\$ 21,437$ & $\$ 2,368$ & $\$ 28,444$ \\
\hline $\begin{array}{l}\text { Total two year follow-up } \\
\left(\chi^{2}{ }_{3}=47.8, P<0.001\right)\end{array}$ & $(51,498)$ & $(21,952)$ & $(18,068)$ & $(951)$ & $(3,810)$ \\
\hline $\begin{array}{l}\text { Total follow-up } \\
(106 \text { cases }) \\
\quad\left(\chi^{2}{ }_{3}=45.1, P<0.001\right)\end{array}$ & $\begin{array}{l}\$ 251,590 \\
(154,258)\end{array}$ & $\begin{array}{r}\$ 139,252 \\
(55,877)\end{array}$ & $\begin{array}{l}\$ 51,056 \\
(37,460)\end{array}$ & $\begin{array}{r}\$ 11,907 \\
(9,574)\end{array}$ & $\begin{array}{l}\$ 58,540 \\
(19,089)\end{array}$ \\
\hline \multicolumn{4}{|l|}{$\left(\chi_{3}^{2}=45.1, P<0.001\right)$} & & \\
\hline $\begin{array}{l}\text { mean } \\
(106 \text { cases })\end{array}$ & $\$ 507,085$ & $\$ 380,401$ & $\begin{array}{l}\$ 214,756 \\
(186963)\end{array}$ & $\$ 63,869$ & $\$ 185,961$ \\
\hline$\quad\left(\chi^{2}{ }_{3}=60.0, P<0.001\right)$ & & & & $(43,3 / 2)$ & \\
\hline $\begin{array}{l}\text { Two year total charge } \\
\text { mean } \\
(115 \text { cases }) \\
\qquad\left(\chi^{2}{ }_{3}=55.4, P<0.001\right)\end{array}$ & $\begin{array}{l}\$ 425,904 \\
(289,620)\end{array}$ & $\begin{array}{l}\$ 387,960 \\
(263,032)\end{array}$ & $\begin{array}{l}\$ 210,630 \\
(176,569)\end{array}$ & $\begin{array}{l}\$ 62,544 \\
(43,375)\end{array}$ & $\begin{array}{r}\$ 188,933 \\
(120,316)\end{array}$ \\
\hline
\end{tabular}

*Includes attendent care, paid and unpaid comparable costs, registered nursing and household assistance 


\title{
Figure 2: Initial Hospitalization and Follow-up Charges
}

\author{
by injury group \\ (intial: $n=113$; follow-up: $n=106$ ) *
}

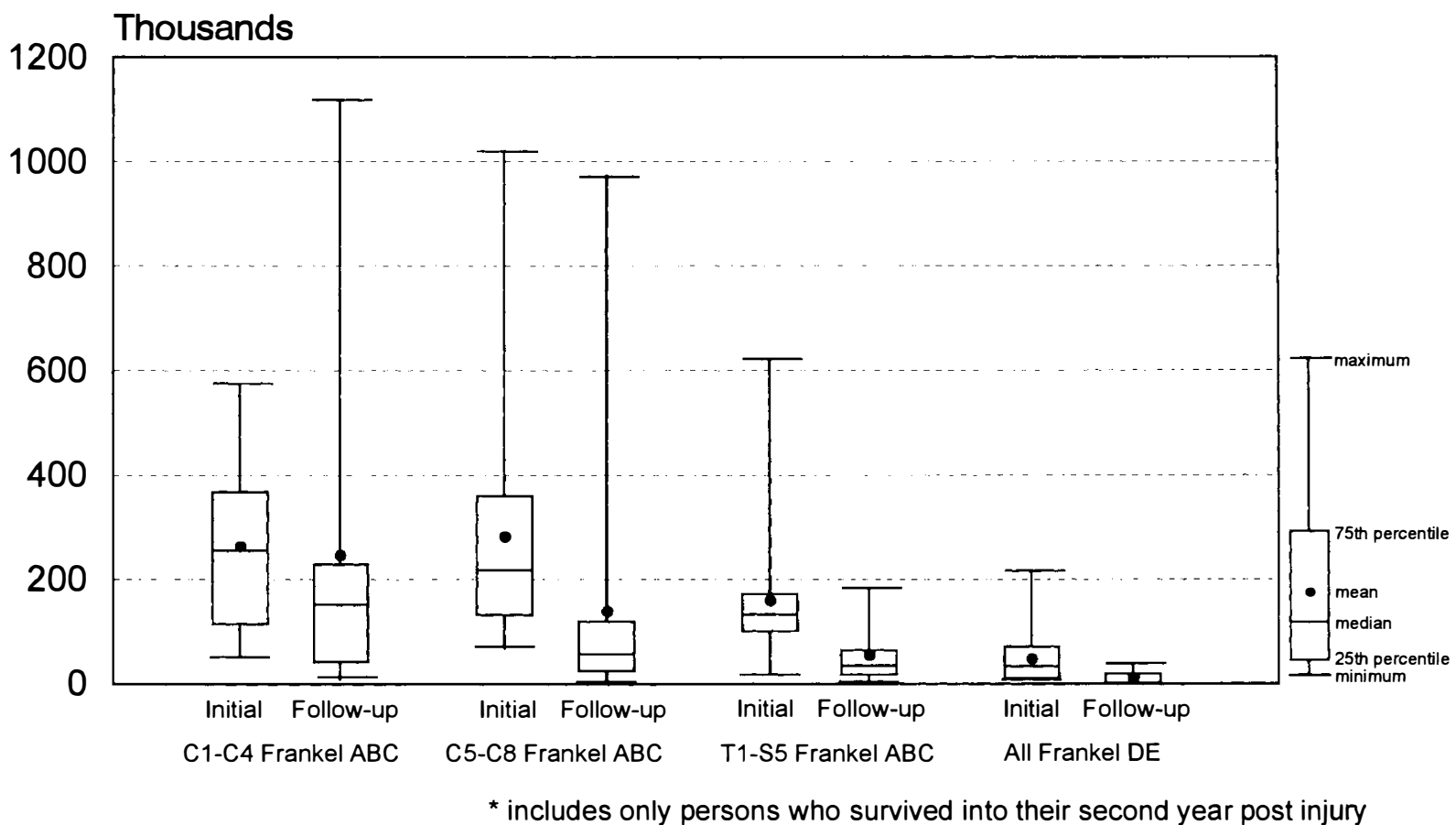

Table 4 Follow-up charges attributable to general follow-up or secondary complications. (1992 Dollars, $n=111)$

\begin{tabular}{|c|c|c|c|}
\hline Service category & $\begin{array}{c}\text { General } \\
\text { Follow-up* }\end{array}$ & $\begin{array}{c}\text { Secondary } \\
\text { Complication }\end{array}$ & Total \\
\hline \multicolumn{4}{|l|}{ Readmissions } \\
\hline (including extended care) & $\$ 6,523$ & $\$ 1,127,517$ & $\$ 1,134,040$ \\
\hline Outpatient services & $\$ 256,933$ & $\$ 468,740$ & $\$ 725,673$ \\
\hline Physician services & $\$ 33,261$ & $\$ 393,204$ & $\$ 426,465$ \\
\hline \multicolumn{4}{|l|}{ Durable medical equipment and } \\
\hline home modifications & $\$ 1,112,271$ & $\$ 479$ & $\$ 1,112,750$ \\
\hline Medication and medical supplies & $\$ 249,683$ & $\$ 42$ & $\$ 249,725$ \\
\hline In-home care & $\$ 2,447,898$ & $\$ 2,618$ & $\$ 2,450,605$ \\
\hline Miscellaneous & $\$ 171,610$ & $\$ 2,408$ & $\$ 174,018$ \\
\hline Total Follow-up Dollars & $\$ 4,278,269$ & $\$ 1,995,008$ & $\$ 6,273,277$ \\
\hline
\end{tabular}

*In three cases where routine follow-up was conducted in conjunction with treatment of a secondary complication the mean routine follow-up charge found in this study was used to estimate the portion of charges attributable to the follow-up care

broad categories - $\$ 4,278,269(68.2 \%)$ for general follow up and $\$ 1,995,008(32.8 \%)$ for the treatment of secondary complications. Within the general follow-up category, in-home care (including both inhome nursing and attendant care) accounted for over half of the expense $(57.2 \%)$ with equipment and home modifications accounting for another fourth $(26.0 \%)$. Only $6.9 \%$ of general follow-up was spent on inpatient, outpatient, or physician charges associated with routine evaluations. Within the category of secondary conditions, over half of the expense was due to inpatient readmissions $(56.5 \%)$ with outpatient services $(23.5 \%)$ and physician charges $(19.7 \%)$ being the other two large categories.

During the follow-up periods, 91 of the participants had documented one or more occurrence of receiving medical care for either general SCI follow-up or for a secondary complication. A total of 457 occurrences of either general follow-up or a secondary complication were identified by ICD-9 codes that had been coded in 
Table 5 Charges associated with general follow-up evaluation and specific body system complications (1992 Dollars, $n=111)$

\begin{tabular}{|c|c|c|c|c|}
\hline Body system & $\begin{array}{l}\text { Frequency } \\
\text { (number of } \\
\text { occurences) }\end{array}$ & $\begin{array}{c}\text { Frequency for which } \\
\text { costs could be } \\
\text { associated }\end{array}$ & Total charges & $\begin{array}{c}\text { Charges per } \\
\text { occurence } \\
\text { mean } \\
\text { (median) }\end{array}$ \\
\hline Urological/bladder/renal & 60 & 23 & $\$ 26,833$ & $\begin{array}{r}\$ 1,167 \\
(368)\end{array}$ \\
\hline Skin & 43 & 14 & $\$ 242,217$ & $\begin{array}{r}\$ 17,301 \\
(8,284)\end{array}$ \\
\hline Pain & 38 & 8 & $\$ 1,868$ & $\begin{array}{l}\$ 233 \\
(244)\end{array}$ \\
\hline Gastro-intestinal & 37 & 6 & $\$ 5,046$ & $\begin{array}{l}\$ 841 \\
(577)\end{array}$ \\
\hline Muscular/spasticity & 34 & 9 & $\$ 11,413$ & $\begin{array}{r}\$ 1,268 \\
(82)\end{array}$ \\
\hline Neurological & 33 & 8 & $\$ 178,566$ & $\begin{array}{l}\$ 22,321 \\
(17,883)\end{array}$ \\
\hline Orthopedic & 28 & 14 & $\$ 176,411$ & $\begin{array}{l}\$ 12,601 \\
(10,238)\end{array}$ \\
\hline Circulatory & 19 & 7 & $\$ 52,389$ & $\begin{array}{l}\$ 7,484 \\
(6,227)\end{array}$ \\
\hline Concomitant injury & 19 & 19 & $\$ 56,180$ & $\begin{array}{l}\$ 2,957 \\
(1,737)\end{array}$ \\
\hline Injury & 16 & 9 & $\$ 81,010$ & $\begin{array}{l}\$ 9,001 \\
(1,062)\end{array}$ \\
\hline Respiratory & 14 & 8 & $\$ 106,192$ & $\begin{array}{r}\$ 13,274 \\
(7,688)\end{array}$ \\
\hline Physcological & 12 & 8 & $\$ 21,022$ & $\begin{array}{l}\$ 2,628 \\
(2,456)\end{array}$ \\
\hline Enodcrine & 11 & 0 & - & - \\
\hline Gynecological & 9 & 0 & - & - \\
\hline Fatigue & 1 & 0 & - & - \\
\hline Total Complications & 374 & & & \\
\hline $\begin{array}{l}\text { Total attributable to a single } \\
\text { complication }\end{array}$ & & 133 & $\$ 959,148$ & $\begin{array}{r}\$ 7,212 \\
(1,280)\end{array}$ \\
\hline $\begin{array}{l}\text { Total attributable to multiple } \\
\text { complications }\end{array}$ & & 241 & $\$ 1,035,860$ & $\$ 4,298$ \\
\hline General follow-up & 83 & 83 & $\$ 298,311$ & $\begin{array}{l}\$ 3,594 \\
(2,469)\end{array}$ \\
\hline
\end{tabular}

conjunction with services provided to these 91 participants. Of these 457 occurrences, 83 were for general follow-up and 374 were for secondary complications. This is less than one general follow-up occurrence per person during the 2 years and is more than three medical occurrences per person for complications during that same 2-year period.

In 133 of the 374 instances of treatment for secondary complications, only one complication presented and the charges could be attributed directly to that complication. The remaining 241 complications presented in multiple occurrences where more than one complication was treated simultaneously and costs could not be split among the complications. Costs were approximately equally divided among these categories - $\$ 959,148$ for individual complications and $\$ 1,034,860$ for multiple complications.

A complete breakdown of both the frequency and expense associated with each complication of a body system is presented in Table 5. Urological and skin complications were the most frequently identified complications. It was skin, neurologic and orthopedic complications that had the most total costs directly attributable to a specific body system. On the other end of the spectrum gynecological, endocrine and fatigue-related complications were identified, but in no case could specific dollars be attributed to them.

The secondary conditions and complications were represented in varying proportions among the four injury severity groups. The participants with high tetraplegia experienced respiratory and neurological complications as the highest expense categories. The eight participants with high tetraplegia who survived into the follow-up period reported a total of 60 complications or 7.5 complications per person. Fifteen of the participants with low tetraplegia, survived into the follow-up period. These participants had their highest charges associated with skin and neurological complications. This group reported a total of 81 complications or 5.4 complications per 
Table 6 Comparison of first year charges with other published results by injury group (1992 Dollars)

\begin{tabular}{|c|c|c|c|}
\hline & $\begin{array}{c}\text { Current study } \\
\mathrm{n}=111\end{array}$ & $\begin{array}{c}\text { DeVivo et al. } \\
\mathrm{n}=227\end{array}$ & $\begin{array}{c}\text { Berkowitz } \\
\text { et al. } \mathrm{n}=758\end{array}$ \\
\hline Total mean(median) & $\begin{array}{l}\$ 162,214 \\
(116,974)\end{array}$ & $\begin{array}{l}\$ 198,335 \\
(161,110)\end{array}$ & $\$ 126,734$ \\
\hline $\begin{array}{l}\text { Group } 1 \\
\text { Frankel A,B,C } \\
\text { C1-C4 }\end{array}$ & $\begin{array}{l}\$ 371,517 \\
(311,445)\end{array}$ & $\begin{array}{l}\$ 417,067 \\
(404,033)\end{array}$ & $N / A$ \\
\hline $\begin{array}{l}\text { Group } 2 \\
\text { Frankel A,B,C } \\
\text { C5-C8 }\end{array}$ & $\begin{array}{l}\$ 347,157 \\
(241,435)\end{array}$ & $\begin{array}{l}\$ 269,324 \\
(249,264)\end{array}$ & $\mathrm{N} / \mathrm{A}$ \\
\hline Complete tetraplegia & $\mathrm{N} / \mathrm{A}$ & $\mathrm{N} / \mathrm{A}$ & $\$ 181,082$ \\
\hline $\begin{array}{l}\text { Group } 3 \\
\text { Frankel A,B,C } \\
\text { T1-S5 }\end{array}$ & $\begin{array}{l}\$ 185,900 \\
(149,110)\end{array}$ & $\begin{array}{l}\$ 152,396 \\
(137,756)\end{array}$ & $\mathrm{N} / \mathrm{A}$ \\
\hline Complete paraplegia & $\mathrm{N} / \mathrm{A}$ & $\mathrm{N} / \mathrm{A}$ & $\$ 135,166$ \\
\hline $\begin{array}{l}\text { Group } 4 \\
\text { Frankel D,E } \\
\text { All levels }\end{array}$ & $\begin{array}{l}\$ 60,267 \\
(42,299)\end{array}$ & $\begin{array}{l}\$ 122,914 \\
(116,694)\end{array}$ & $\mathrm{N} / \mathrm{A}$ \\
\hline $\begin{array}{l}\text { Incomplete tetraplegia } \\
\text { Incomplete paraplegia }\end{array}$ & $\begin{array}{l}\text { N/A } \\
\text { N/A }\end{array}$ & $\begin{array}{l}\text { N/A } \\
\text { N/A }\end{array}$ & $\begin{array}{l}\$ 153,197 \\
\$ 87,799\end{array}$ \\
\hline
\end{tabular}

*The results from Economic Consequences are not directly comparable

person. For the participants with paraplegia, the largest expenses were seen in the categories of neurological, skin and orthopedic complications. All 36 of these participants survived into the follow-up period and they reported a total of 187 complications or 5.2 complications per person. Similarly, the participants with incomplete paralysis experienced their highest charges in the areas of orthopedic, skin and neurological complications. Again, all 52 of these participants survived into the follow-up period and they reported a total of 46 complications or 0.9 complications per person.

\section{Discussion}

These data present for the first time a cost picture of spinal cord injury as it occurs in a population. The volume of costs that are presented here are supportive of previous SCI cost-related work in that they are consistent with the finding that cost of injury is highly correlated with severity of injury. This correlation is now documented not only among survivors treated at a SCI Model Systems of Care, but also among the population of all SCI survivors. Of the 115 persons, in this study, $30 \%$ used no inpatient rehabilitation services, $40 \%$ of them received rehabilitation at the Regional Spinal Cord Injury Model System and 30\% received rehabilitation at other area rehabilitation units. At the same time these data substantially add to the accuracy of our knowledge, as it relates to persons with spinal cord injuries who experience enough recovery during the acute phase that they do not require inpatient rehabilitation.

In applying these data to large groups of SCI survivors it is important to keep in mind the effect of case mix on total overall costs. It is possible that the case mix of this study examining 1 year of SCI survivors in Colorado is not representative of the case mix of all injuries occurring nationally. However, the mix of patients represented here is indeed representative of the case mix of cases in Colorado from 1990 to $1993 .+\dagger$

As the data presented here are applied to individual cases for cost projection purposes a few limitations must be considered. First, although the size of the entire population is fairly large, 115 persons, when divided into the four groups, based on injury level and severity, the number of persons in the two most severe categories is quite small. Additionally, the cost is quite variable and skewed as can be seen in Figure 2. Both of these together lead to a decreased confidence in the precision of the mean as it applies to any specific individual. Further research with larger samples of severe injury survivors will be valuable.

Another consideration, in applying these data to the individual case, is that these costs represent the services that have been rendered, not the services that were optimal for care. In fact many services could have been needed and not rendered. And finally, in regards to applying cost data to the individual case for cost projection purposes, experienced clinical judge-

$\dagger \dagger$ In the current study the case mix was Group 1-10\%; Group 2$14 \%$; Group 3-31\%; and Group 4-45\%. During the 1990 to 1993 interval the case mix was Group 1-9\%; Group 2-16\%; Group 3$22 \%$; and Group 4: $50 \% .{ }^{21}\left(\chi_{3}^{2}=2.46, P=0.48\right)$ 
ment concerning the medical course of a specific individual with an extremely complicated course must be considered.

Comparisons between this study and the two most recent comprehensive SCI cost publications are displayed in Table 6. In comparing this study with DeVivo et al differences between the two studies in the first year total mean cost were significant for the participants with incomplete paralysis $(\$ 122,914$ in DeVivo et al vs $\$ 60,267$ in the current study, $\left.\mathrm{t}_{128}=5.79, P<0.001\right)$. Differences in cost were not significant for either the high tetraplegia group, the low tetraplegia group or the paraplegic group. Similarly, when adjusted for severity of case mix, the overall first year means are not significantly different. The significant difference among the incomplete paralysis group is a direct reflection of the 30 Frankel D or E participants, in the current study, who did not go to inpatient rehabilitation.

An additional difference between the DeVivo et al sample and the one used here is the time frame in which the measures of injury classification were determined. Injury group classification was determined at the time of acute care discharge for this study and at either the time of rehabilitation discharge or reevaluation in the DeVivo et al study. It is possible that some of the Group 1, 2 and 3 participants had experienced recovery and changed groupings during the course of the study. If patients changed groups in this direction the mean charges of all groups would be increased. This, however, would not effect the total mean charges experienced by the entire group.

Despite the differences between the participant classification methodology used by Berkowitz et al and that used here and by DeVivo et al a couple of trends can still be observed (but not tested for significance) after the dollars presented are adjusted to 1992. First, for participants with functionally complete injuries, the Berkowitz study consistently estimated costs much lower than the actual documented costs found by both DeVivo et al and this study. This difference is not adequately explained by the classification scheme, since the scheme utilized by Berkowitz et al would have suggested higher rather than lower costs. Given the greater accuracy of cost ascertainment by DeVivo et al and this study, it would appear that their higher cost data are more valid.

While for complete injuries Berkowitz consistently estimated lower cost, for incomplete injuries Berkowitz et al estimated higher first year costs for incomplete paralysis participants. This again demonstrated the impact of a population-based sample of Frankel D and $\mathrm{E}$ injuries, which consistently lowers the cost experience of this group.

The Price, et al classification scheme, like the Berkowitz scheme, is not directly comparable to that presented in this study. However, among the acute care and rehabilitation costs presented, it is observed that the total median cost $(\$ 53,410,1989$ dollars) for all patients receiving acute care and rehabilitation when inflated to the 1992 dollar level $(\$ 65,630)$ is considerably less than the total median $(\$ 104,355)$ initial hospitalization charges presented here. An important and costly difference is that the current study includes physician charges during this hospitalization period, where as Price et al does not.

These population-based data allow more accurate planning of the resources needed in providing medical services to persons who have sustained a traumatic spinal cord injury within a population as a whole. Persons sustaining tetraplegia account for $23 \%$ of the persons injured annually, and they utilized $46 \%$ of the initial hospitalization dollars spent and $61 \%$ of the follow-up dollars. Persons who sustained paraplegia account for $31 \%$ of the persons injured annually, and they utilize $37 \%$ of the initial hospitalization dollars and $29 \%$ of the follow-up dollars. Finally, the persons who sustained functionally incomplete paralysis who comprise $45 \%$ of the annual injuries, consumed $17 \%$ of the initial inpatient charges and $10 \%$ of the follow-up charges. The large amount of follow-up dollars consumed by persons with tetraplegia are in large part due to the cost of in-home care. Thirty-nine percent ( $\$ 2.5$ million) of the follow-up dollars were spent on in-home care. Of these in-home care expenditures, $90 \%$ went for services provided to persons with tetraplegia, $7 \%$ to persons with paraplegia, $3 \%$ to persons with incomplete paralysis. Additionally, persons with both high and low tetraplegia had higher rates of complications than did persons with either paraplegia or incomplete paralysis.

These data also allow more accurate planning of the resources needed in both planning for and providing intervention of complications secondary to SCI. As one considers the impact of this secondary complications data for the purpose of prevention, two approaches could be taken. First, one could target the most frequently reported body systems in which complications occur. Using this approach the targeted body systems would be urological, skin, pain and gastro-intestinal related, which account for $48 \%$ of the complications. A second approach is to target the most expensive complications. This would direct interventions at the neurological, skin, respiratory and orthopedic complications. These four categories of follow-up costs account for $57 \%$ of the follow-up dollars that were identified as attributable to a specific body system.

In evaluating secondary complications we were not able to separate the charges for complications that occurred simultaneously. While this has the potential of either over or under estimating the cost of specific complications, it should be noted that the average cost of unattributable complications was less than the average cost of complications where costs could be attributed.

In preventing secondary complications, closer routine follow-up may be warranted. The present study demonstrated that the dollars spent on treating 
secondary complications was over six times greater than the dollars spent on routine medical evaluations. On the other hand, many of the participants in this study reported complications in the high cost categories before they became high cost. This indicates that complications can potentially be identified when they are in less severe and less costly stages and interventions implemented.

\section{Acknowledgements}

Funding for this research was provided through a cooperative agreement for the prevention of disabilities, awarded to the Colorado Department of Public Health and Environment by the Centers for Disease Control and Prevention. A special thanks to William Marine, MD, MPH and Anna Baron, PhD from the University of Colorado Health Sciences Center, for their critical review in the preparation of this manuscript.

\section{References}

1 Rice DP, MacKenzie EJ et al. Cost of Injury in the United States: A Report to Congress. Institute for Health \& Aging, University of California and Injury Prevention Center, The Johns Hopkins University, San Francisco, CA, 1989.

2 Berkowitz M, Harvey C, Green CG, Wilson SE The Economic Consequences of Traumatic Spinal Cord Injury. Paralyzed Veterans of America: Demos, Washington, DC, 1990.

3 Harvey C, et al. New Estimates of the Direct Costs of Traumatic Spinal Cord Injuries: Results From a Nationwide Survey. Paraplegia 1992; 30: $834-850$.

4 DeVivo MJ, Whiteneck GG, Charles ED. Chapter 12: The Economic Impact of Spinal Cord Injury. Spinal Cord Injury: Clinical Outcomes from the Model Systems. Ed. S Stover, J Delisa and G Whiteneck. Aspen Publishers, Inc., New York, NY, 1995.

5 Smart CN, Charles N, Sanders CR. The Costs of Motor Vehicle Related Spinal Cord Injuries. Insurance Institute for Highway Safety, Washington, DC, 1976.

6 Hartunian NS, Smart CN, Thompson MS. The Incidence and Economic Costs of Major Health Impairments: A Comparative Analysis of Cancer, Motor Vehicle Injuries, Coronary Heart Disease, and Cancer. D.C. Heath and Company, Lexington, MA, 1981.
7 Webb SB Jr., Berzins E, Wingardner TS, Lorenzi ME. First year hospitalization costs of the spinal cord injured patient. Paraplegia 1778; 15: $311-318$.

8 Webb SB Jr., Berzins E, Wingardner TS, Lorenzi ME. Spinal cord injury: epidemiologic implications, costs, and patterns of care in 85 patients. Arch Phys Med Rehabil 1979; 60: 335-340.

9 Charles ED, et al. The costs of spinal cord injury. Paraplegia 1978; 15: 302-310.

10 DeVivo MJ, Potter MY, Stover SL, Fine PR. Costs of acute care and rehabilitation for spinal cord in jury patients [Abstract]. Arch Phys Med Rehabil 1987; 68: 657.

11 Fine PR, Stover SL, DeVivo MJ. A methodology for predicting lengths of stay for spinal cord injury patients. Inquiry 1987; 24: $147-156$.

12 Whiteneck GG, et al. The Management of High Quadriplegia. Comprehensive Neurologic Rehabilitation. 1 ed. 3 vols., Demos, New York, NY, 1989.

13 Whiteneck, GG. The High Costs of High-level Quadriplegia. In: Apple Dr Jr, Hudson LM, Eds. Spinal cord in jury: the model. The Georgia Regional Spinal Cord Injury Care System, Atlanta, GA, 1990.

14 Charles ED, Van Matre JG, Miller JM. Spinal cord injury - A cost benefit analysis of alternative treatment models. Paraplegia 1974; 12: $222-231$.

15 DeVivo MJ, Stover SL, Fine PR. The relationship between sponsorship and rehabilitation outcome following spinal cord injury. Paraplegia 1989; 27: 470-479.

16 Tator $\mathrm{CH}$, et al. Complications and costs of management of acute spinal cord in jury. Paraplegia 1993; 31: 700-714.

17 Meyers AR, et al. Rehospitalization and spinal cord injury: cross-sectional survey of adults living independently. Arch Phys Med Rehabil 1985; 66: 704-708.

18 Meyers AR, Branch LG, Cupples LA, Lederman RI, Feltin M, Master RJ. Predictors of medical care utilization by independently living adults with spinal cord injuries. Arch Phys Med Rehabil 1989; 70: 471-476.

19 Price C, Makintubee S, Herndon W, Istre G. Epidemiology of Traumatic Spinal Cord Injury and Acute Hospitalization and Rehabilitation Charges for Spinal Cord Injuries in Oklahoma. 1988-1990. Am J Epidemiol 1994; 139: 37-47.

20 Frankel HL, et al. The value of postural reduction in the initial management of closed injuries to the spine with paraplegia and tetraplegia. Paraplegia 1969; 7: 179-192.

21 Colorado Department of Health. 1993 Annual Report of The Spinal Cord Injury Early Notification System. Colorado Department of Transportation Printing Office, Denver, CO, 1994.

22 Kraus, et al. Incidence of traumatic spinal cord lesions. J Chron Dis 1975; 28: 471 - 492 . 